\title{
Erratum to: Molecular Physical Chemistry
}

José J.C. Teixeira-Dias

\section{Erratum to: \\ J.J.C. Teixeira-Dias, Molecular Physical Chemistry, DOI 10.1007/978-3-319-41093-7}

In the original version of the book, the belated corrections in Index page have to be incorporated. The erratum book has been updated with the change. 